\title{
The United Kingdom Childhood Cancer Study of exposure to domestic sources of ionising radiation: 2: gamma radiation
}

\section{UK Childhood Cancer Study Investigators*,1,2}

'UKCCS, University of Leeds, Institute of Epidemiology, 30 Hyde Terrace, Leeds LS2 9LN, UK

\begin{abstract}
This article reports measurements of household levels of gamma and cosmic rays at the addresses of children with cancer at the time of diagnosis and six months before, and of similar data at the addresses of control children. There is no indication of increased risk with increasing dose rates either in matched or unmatched analyses, with or without adjustment for deprivation. Sub-division by diagnostic group did not reveal any association with any specific types of malignancy. Studies of the relationship between household gamma rays and radon concentration show no evidence of any interactions.

British Journal of Cancer (2002) 86, 1727 - 1731. doi: I0.1038/sj.bjc.6600277 www.bjcancer.com

(c) 2002 Cancer Research UK
\end{abstract}

Keywords: childhood cancer; gamma dose rate; radon interactions; acute lymphoblastic leukaemia; non-Hodgkin's lymphoma; central nervous system tumours

The United Kingdom Childhood Cancer Study had, as one of its a priori hypotheses, that ionising radiation from natural sources within households might cause childhood cancer. To address this question separate household measurements were made of radon gas concentration and of penetrating external radiation (predominantly from terrestrial gamma rays and cosmic rays). Whilst there was special interest in the biological effects of high linear energy transfer (LET) irradiation from radon and its short term decay products (UKCCS Investigators, 2002), there was little reason to think that there would be detectable haematological effects arising from differential exposures to domestic gamma ray radiation. Risk estimates, based on standard radiological protection approaches, have suggested that up to about $20 \%$ of childhood and young adult leukaemias (aged 0-24) in the UK could be due to natural low-LET radiation, including terrestrial gamma rays (COMARE, 1996; Simmonds et al, 1995). However, variation in gamma ray levels between households are likely to be quite modest. There are few published studies of possible childhood cancer risks from domestic gamma ray levels. One correlation study has suggested that there may be a negative trend in risk for childhood leukaemia associated with domestic gamma levels (Muirhead et al, 1992). This trend was partially reversed when administrative district data were analysed with adjustment for counties. However, a subsequent study, which also adjusted for area socio-economic status, showed no association (Richardson et al, 1995).

There have been many studies of terrestrial and cosmic gamma ray from many countries recording natural (and local) variation in dose rate (UNSCEAR, 1993). The UK study of this type (Wrixon et al, 1988), conducted by the National Radiological Protection Board (NRPB) with data on over 2000 households from measurements

\footnotetext{
*Correspondence: RA Cartwright; E-mail: UKCCS@Irf.leeds.ac.uk

${ }^{2}$ See end of article for full list of investigators.

Received 19 November 200I; revised 4 March 2002; accepted 4 March 2002
}

taken in the 1980's, allows comparisons with the results of the present study.

\section{METHODS}

The UKCCS was designed as a population-based matched casecontrol study covering the whole of Great Britain. Ten regional centres (Figure 1) administered the same study protocol, with minor regional modification to satisfy local ethical committee approval and practical considerations. The study methods are given in more detail elsewhere (UKCCS Investigators, 2000).

\section{Study subjects}

During the study period, all children with malignant neoplasms aged under 15 years in England, Wales and Scotland were registered through liaison with oncologists and paediatricians. The study began accruing cases in 1991 for Scotland and in 1992 for England and Wales. Scotland terminated case registration at the end of 1994. In England and Wales, registration of solid tumours was terminated at the end of 1994, of non-Hodgkin's lymphoma in 1995, and of leukaemias in 1996. All neoplastic diagnoses were submitted for central pathological review.

With few exceptions, each case had two randomly selected controls, matched by sex, calendar month of birth and (former) Family Health Services Authority (England and Wales) or Scottish Health Board of residence. Children were eligible if they were born in Great Britain, had no prior malignancy and were not in local authority care. Subjects were ineligible if they themselves or their parents had lived outside Great Britain for the three months leading up to diagnosis. Eligible controls who declined to participate were replaced until two controls were enrolled (UKCCS Investigators, 2000).

\section{Measurement of gamma radiation}

A face-to-face interview was conducted with each child's parents, covering social, occupational and medical histories of the child 


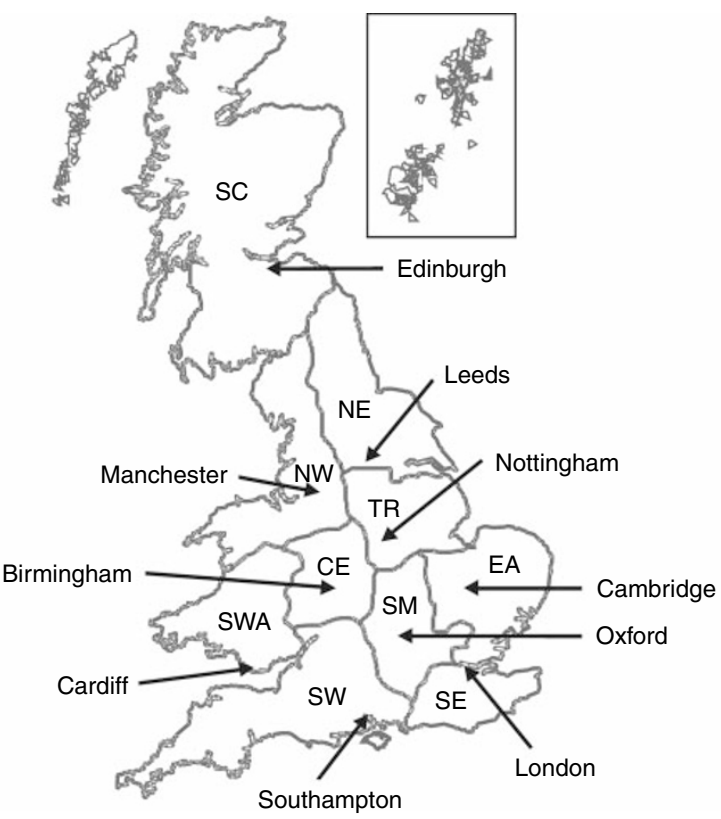

Figure I Regions and study centres of the UKCCS. UKCCS study regions: SC Scotland; NE North-east; NW North-west; TR Trent; CE Central; EA East Anglia; SM South Midlands; SWA South-Wales; SW South-west; SE South-east

and parents. A full residential history for the child was also collected and all addresses lived in by the child for 6 months or more were targeted for measurement. A written request to participate was then made to each residence. Following agreement, two radon and two thermoluminescent dosimeters (TLD) or 'gamma' detectors were sent to each household with instructions to place one of each in the main bedroom and in the main living area. After 6 months had elapsed a letter was sent recalling the detectors, which were returned to the NRPB for processing and measurement of the cumulative exposure. This study reports on the results of the address of the case at diagnosis, that is, those who had lived at that address for at least the previous 6 months.

The system used for passive environmental photon monitoring consisted of a modification of a standard body TLD used for personal photon monitoring and the assessment of dose is based on two 30\% LiF;Mg; Ti detector elements. These detectors respond to all types of penetrating ionising radiation including terrestrial gamma rays and secondary particles resulting from cosmic rays.

The results are expressed as absorbed dose to air. Annual estimates are in micro gray ( $\mu \mathrm{Gy})$ per year and hourly dose rates in nano gray (nGy) per hour. The results given in this study include the dose from cosmic rays; this varies with height above sea level, but differences within the UK are small. The mean has been estimated to be $32 \mathrm{nGy}$ per hour (UNSCEAR, 2000) or $280 \mu \mathrm{Gy}$ per year.

The main problems encountered with the detectors were occasional damaged detectors, faulty readouts, and differences between the recorded doses on the two detectors of greater than $20 \%$. In all these cases the result was excluded from the analysis. It is estimated that this occurred for between 5 and $10 \%$ of measurements. Where the readings of the two detectors differed by less than $20 \%$, the mean value was used. Doses accumulated away from the household of measurement were allowed for by subtracting $2.3 \mu \mathrm{Gy}$ for each day in storage, and $0.9 \mu \mathrm{Gy}$ for each day in transit.

Detectors were intended to be in place for 6 months but the period over which measurements were actually made varied. The analyses were restricted to the measurements of the doses that had accumulated with the detectors in place within a household for both living-room and bedroom for between 5 and 7 months. Over $99 \%$ of all detectors met this requirement.

\section{Deprivation scores}

An area-based index of deprivation for the child's residence at the time of diagnosis, and 6 months before, based on an index used in a previous study of childhood leukaemia (Draper et al, 1991), was used to provide a proxy socio-economic adjustment (UKCCS, 2000). The index was calculated for the smallest 1991 census area, that is an enumeration district (ED) in England and Wales or an output area $(\mathrm{OA})$ in Scotland. Proportions of the following variables within each ED/OA were calculated: economically active persons unemployed, households with no car, households not owner-occupied, and overcrowded households (more than one person per room). The variables were log-transformed (to reduce skewness to zero), standardised (mean of zero and standard deviation of one) and the standard deviates summed for each ED/OA. The deprivation index was used to provide seven categories, with equal numbers of ED/OA's in each category. Greater values in the deprivation index represent greater deprivation. All targeted houses were given a validated postal code and allocated to an ED or OA from the 1991 census.

\section{Statistical analysis}

All statistical analyses were performed using Stata version 6 (Stata Corporation, 1998). All estimates of risk are presented as odds ratios, derived using conditional logistic regression modelling. To check that data for incomplete sets, dropped after matching, did not unduly influence the results, all analyses were repeated with logistic regression modelling, adjusted for age and sex (the matching variables). The data were checked for confounding between socio-economic status and household gamma.

\section{RESULTS}

The parents of 3838 children with cancer and 7629 children without cancer were interviewed, representing $87 \%$ of eligible cases and $64 \%$ of eligible controls. Following interview, measurements were obtained from the home at diagnosis of 2165 cases and 5086 controls. Nearly all (97\%) estimates were based on readings obtained from both the bedroom and the living room.

The case household participation for TLD 'gamma' detection was virtually identical to that for radon measurements. Thus all the issues that arose from the differential response rates of the case and control families and from the overall response rates are similar to those discussed in the accompanying radon paper (UKCCS, 2002). Table 1 gives details of what happened to the detectors after they were sent to those households which agreed to participate. The study accrued results from over 10000 households. Figure 2 shows the distribution of gamma rays results from the 5086 control households, showing a mean annual absorbed dose of $843 \mu \mathrm{Gy}$ with individual values varying from undetectable levels (i.e. under $100 \mu \mathrm{Gy}^{-1}$ ) to a maximum of $2027 \mu \mathrm{Gy} \mathrm{y}^{-1}$.

Table 2 gives the control measurements reported for nine regions (two, Central and South Wales being combined) and for the seven socio-economic groups. The mean household dose rates vary throughout the country: the highest levels being in the North East Region of England and Trent and the lowest in the South West Region of England (See Figure 1). This is commented on in the discussion. The mean dose rates vary with deprivation score, the most deprived households having the highest mean dose rate. Although there are trends in the dose rates by deprivation, and there is also an apparent geographical variation, neither set of results is statistically significant due to the wide scatter of results and the consequentially high standard deviations. 
Table I *TLD measurements for all houses where attempts were made to record measurements (household of the case at the time of diagnosis and its equivalent control address)

\begin{tabular}{|c|c|c|c|c|c|c|}
\hline & \multicolumn{2}{|c|}{ Cases } & \multicolumn{2}{|c|}{ Controls } & \multicolumn{2}{|c|}{ Total } \\
\hline & Detectors & Houses & Detectors & Houses & Detectors & Houses \\
\hline Total from interviewed subjects (\%) & $8059(100)^{* * *}$ & $4002(100)$ & $12542(100)$ & $6244(100)$ & $20601(100)$ & $10246(100)$ \\
\hline $\begin{array}{l}\text { Measurement valid } \\
\text { Both rooms } \\
\text { Bedroom only } \\
\text { Living room only }\end{array}$ & $\begin{array}{c}6511(81) \\
6384(79) \\
61(1) \\
66(1)\end{array}$ & $\begin{array}{c}3319(83) \\
3192(80) \\
61(2) \\
66(2)\end{array}$ & $\begin{array}{l}9977(80) \\
9762(78) \\
71(1) \\
134(1)\end{array}$ & $\begin{aligned} & 5086(81) \\
& 488 \mid(78) \\
& 71(1) \\
& 134(2)\end{aligned}$ & $\begin{array}{l}16488(80) \\
16146(78) \\
132(1) \\
200(1)\end{array}$ & $\begin{array}{c}8405(82) \\
8073(79) \\
132(1) \\
200(2)\end{array}$ \\
\hline
\end{tabular}

*TLD=Thermoluminescent device. **Percentage of total from interviewed subjects in parenthesis.

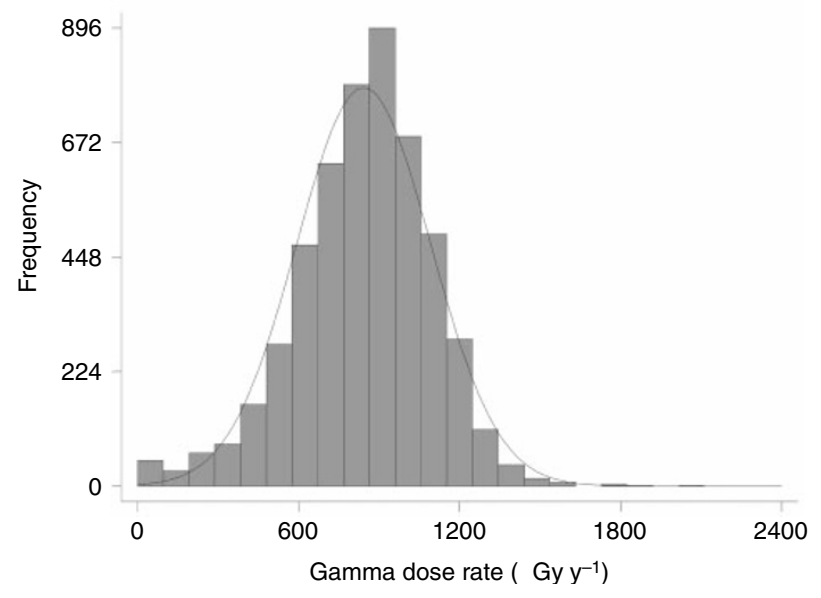

Figure 2 Frequency of absorbed dose rate in control houses.

Studies of dose rate by measurement year and months by region showed little variation over the period of the study (results not shown). Table 3 shows the overall odds ratio (for any cancer) and household dose rate based on quintiles, using both matched and unmatched analyses. The results show no relationship between either crude results or results adjusted for deprivation and increased odds ratios for childhood cancer. Separate data from six diagnostic groups are given in Table 4. There is no suggestion of either an increasing or decreasing risk from any of the groups. For CNS tumours, the odds ratios increase with increasing dose rate only to a maximum of $33 \%$ and the trend is not statistically significant $(P=0.15)$

\section{Radon - Gamma interaction}

The relationships between TLD-derived doses divided into thirds (under 758.1, 758.1-956.6, over 956.6) and radon concentrations split into the five predefined levels (see radon paper, this issue) of $0-24,25-49,50-99,100-199$ and $200+$ $\mathrm{Bqm}^{-3}$ is shown in Table 5. There is no suggestion of any interactions, apart from a weak association at the highest gamma and radon level, which is not statistically significant. When the analyses are conducted using quintiles of radon exposure, no such association appears.
Table 2 Summary of absorbed dose rates for controls by area and deprivation scores

\begin{tabular}{|c|c|c|c|c|c|}
\hline & Number & $\begin{array}{c}\text { Annual } \\
\text { Mean } \\
\left(\mu \mathbf{G} \mathbf{y} \mathbf{y}^{-1}\right)\end{array}$ & $\begin{array}{c}\text { Std Dev } \\
\left(\mu \mathbf{G} \mathbf{y}^{-1}\right)\end{array}$ & $\underset{\left(\mu \mathbf{G} \mathbf{y} \mathbf{g}^{-1}\right)}{\operatorname{Min}}$ & $\begin{array}{c}\operatorname{Max} \\
\left(\mu \mathbf{G} \mathbf{y} \mathbf{g}^{-1}\right)\end{array}$ \\
\hline Total controls & 5086 & 842.5 & 249.9 & 0 & 2027.2 \\
\hline \multicolumn{6}{|l|}{ Region } \\
\hline North-west & 771 & 889.7 & 209.7 & 0 & 1470.5 \\
\hline North-east & 651 & 975.9 & 234.3 & 53.0 & 1614.4 \\
\hline South-west & 649 & 722.6 & 267.6 & 0 & 2027.2 \\
\hline Trent & 487 & 967.1 & 218.5 & 64.5 & 1578.4 \\
\hline $\begin{array}{l}\text { Central \& } \\
\text { South Wales }{ }^{\mathrm{a}}\end{array}$ & 438 & 878.0 & 238.3 & 92.9 & 1429.0 \\
\hline East Anglia & 454 & 736.7 & 234.6 & 0 & 1296.8 \\
\hline South Midlands & 543 & 748.8 & 228.1 & 0 & 1797.4 \\
\hline South-east & 373 & 742.7 & 230.4 & 0 & 1455.2 \\
\hline Scotland & 720 & 862.5 & 224.6 & 0 & 1872.4 \\
\hline \multicolumn{6}{|l|}{ Deprivation score } \\
\hline I Most affluent & 883 & 819.2 & 232.1 & 0 & | 872.4 \\
\hline 2 & 915 & 813.3 & 249.1 & 0 & 1566.9 \\
\hline 3 & 875 & 828.4 & 252.5 & 0 & 1797.4 \\
\hline 4 & 796 & 832.7 & 250.2 & 0 & 1470.5 \\
\hline 5 & 625 & 876.1 & 258.0 & 0 & 2027.2 \\
\hline 6 & 542 & 873.2 & 254.3 & 0 & 1592.9 \\
\hline 7 Most deprived & 450 & 908.8 & 244.1 & 141.2 & 1796.3 \\
\hline
\end{tabular}

${ }^{a}$ Central and South Wales were combined for the purposes of this study.

\section{DISCUSSION}

To our knowledge this is the first case-control study directly measuring domestic gamma ray and cosmic ray levels and relating this to the risk of all childhood cancers. The results relate to the households of the affected children at the time of diagnosis, and are limited to children who had lived at the address for a minimum period of 6 months, the control households having the same limitations. The study is limited by accuracy of the TLD measurements, including inherent detector variability, storage, transport, householder compliance and the assumption of constant cosmic ray dose rate irrespective of altitude of the household. Some indication of combined uncertainties can be obtained from Figure 2. If it is assumed that the dose from cosmic rays is approximately consistent at $34 \mathrm{nGy}$ per hour, then this should produce a reading on all detectors of about $300 \mu \mathrm{Gy}$ per year. The fact that there were some TLD measurements in the below $300 \mu$ Gy per year category (see Figure 2) suggests that these measurements can carry uncer- 
Table 3 Logistic regression modelling of absorbed dose rate in all diagnostic groups

\begin{tabular}{|c|c|c|c|c|c|c|c|}
\hline \multirow[b]{2}{*}{ Variable } & \multirow[b]{2}{*}{ Level } & \multicolumn{2}{|c|}{ Number } & \multicolumn{2}{|c|}{ Matched } & \multicolumn{2}{|c|}{ Unmatched } \\
\hline & & Case & Controls & OR & 95\% Cl & OR & 95\% Cl \\
\hline $\begin{array}{l}\text { Dose rate }\left(\mu \mathrm{G} y \mathrm{y}^{-1}\right) \\
\text { Unadjusted for } \\
\text { deprivation }\end{array}$ & $\begin{array}{c}<650.3 \\
650.3-<798.5 \\
798.5-<916.2 \\
916.2-<1045.3 \\
>=1045.3\end{array}$ & $\begin{array}{l}418 \\
436 \\
459 \\
423 \\
429\end{array}$ & $\begin{array}{l}742 \\
724 \\
702 \\
737 \\
732\end{array}$ & $\begin{array}{l}1 \\
1.09 \\
1.17 \\
1.04 \\
1.00\end{array}$ & $\begin{array}{c}- \\
0.90-1.34 \\
0.95-1.43 \\
0.84-1.29 \\
0.80-1.25\end{array}$ & $\begin{array}{l}1 \\
1.06 \\
1.16 \\
1.02 \\
1.04\end{array}$ & $\begin{array}{c}- \\
0.90-1.26 \\
0.98-1.37 \\
0.86-1.20 \\
0.88-1.23\end{array}$ \\
\hline $\begin{array}{l}\text { Dose rate }\left(\mu G y y^{-1}\right) \\
\text { Adjusted for } \\
\text { deprivation }\end{array}$ & $\begin{array}{c}<650.3 \\
650.3-<798.5 \\
798.5-<916.2 \\
916.2-<1045.3 \\
>=1045.3\end{array}$ & $\begin{array}{l}418 \\
436 \\
459 \\
423 \\
429\end{array}$ & $\begin{array}{l}742 \\
724 \\
702 \\
737 \\
732\end{array}$ & $\begin{array}{l}1 \\
1.10 \\
1.17 \\
1.04 \\
0.97\end{array}$ & $\begin{array}{c}- \\
0.90-1.35 \\
0.95-1.44 \\
0.84-1.29 \\
0.78-1.21\end{array}$ & $\begin{array}{l}1 \\
1.06 \\
1.15 \\
1.00 \\
1.00\end{array}$ & $\begin{array}{c}- \\
0.89-1.25 \\
0.97-1.36 \\
0.84-1.18 \\
0.84-1.19\end{array}$ \\
\hline
\end{tabular}

Table 4 Conditional logistic regression modelling of dose rate $\left(\mu \mathrm{Gy} \mathrm{y}^{-1}\right)$ without and with adjustment for deprivation for specific diagnostic groups

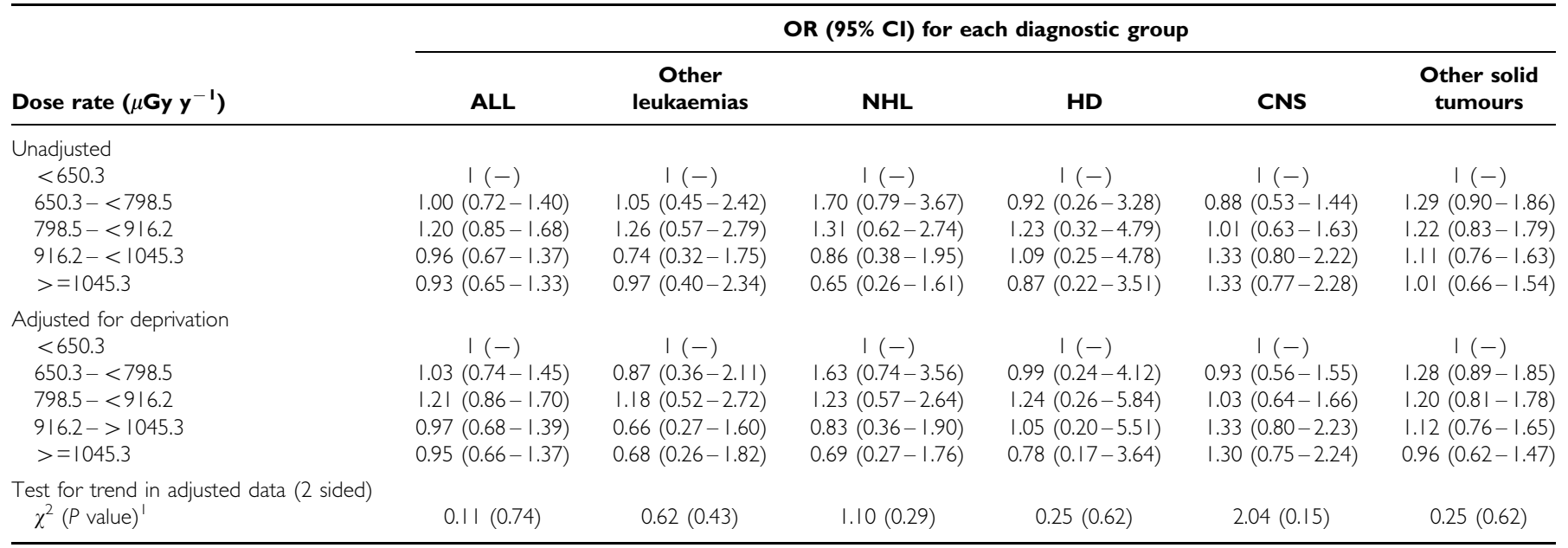

'All have I degree of freedom.

Table 5 Odds ratio of household radon and TLD results - Tertile distribution of TLD $v$ levels of radon, both unadjusted and adjusted for deprivation

\begin{tabular}{|c|c|c|c|c|c|c|c|}
\hline \multirow{2}{*}{\multicolumn{2}{|c|}{$\begin{array}{l}\text { Radon levels } \\
\left(\mathrm{Bq} \mathrm{m}^{-3}\right)\end{array}$}} & \multicolumn{6}{|c|}{ TLD tertiles: case numbers in brackets } \\
\hline & & & & 75 & $957^{*}$ & & \\
\hline \multirow[t]{2}{*}{$0-24$} & unadjusted & 1.0 & (550) & 1.1 & (570) & 1.0 & (543) \\
\hline & adjusted & 1.0 & & 1.1 & & 1.0 & \\
\hline \multirow[t]{2}{*}{$25-49$} & unadjusted & 0.8 & $(107)$ & 0.8 & $(116)$ & $0.7 \dagger$ & $(107)$ \\
\hline & adjusted & 0.8 & & 0.8 & & $0.7 \dagger$ & \\
\hline \multirow[t]{2}{*}{$50-99$} & unadju & $0.6 \dagger$ & (40) & 1.0 & (44) & $0.6 \dagger$ & (48) \\
\hline & adjust & $0.6 \dagger$ & & 1.0 & & 0.6 & \\
\hline \multirow[t]{2}{*}{$100-199$} & unadjusted & 0.5 & (II) & 0.3 & (5) & 0.5 & $(10)$ \\
\hline & adjusted & 0.5 & & 0.3 & & 0.5 & \\
\hline \multirow[t]{2}{*}{$200+$} & unadjusted & 0.7 & (2) & 0.3 & (3) & 1.3 & (8) \\
\hline & adjusted & 0.7 & & 0.3 & & 1.4 & \\
\hline
\end{tabular}

*Gamma dose rate in $\mu \mathrm{Gy} \mathrm{y}^{-1}$. $\uparrow$ Results statistically significant results in $P<0.05$.

tainties of at least $400 \mu \mathrm{Gy}$ per year, or about $50 \%$ of the mean value of the distribution.

Cosmic ray dose rates increase systematically with increasing altitude. However, most of the population live at relatively low altitudes (see below), so it is reasonable to assume the variation in dose rates seen in the analysis is mostly due to terrestrial gamma rays.
The geographical trends in gamma-ray dose rate results by Region that might be expected from knowledge of geological variations are obscured by variation in population density. For example: studies of Wrixon et al (1988) have shown that the environmentally based geographical weighted (outdoor) gamma ray dose rates for Devon and Cornwall are the highest in the UK. However the population weighted (indoor) gamma value for Devon is around the median for county values in the UK. This is because most of the population live in cities and towns such as Plymouth, Exeter and Torbay which are not particularly high gamma ray areas - the population of Dartmoor, a high gamma ray area, is quite low. This is compounded by the grouping into health regions - the Southwest grouping includes, for example, Hampshire with some 600000 homes, whilst Cornwall has only 170000 homes. If data from Wrixon et al (1988) on indoor gamma dose rates are amalgamated (as in the present study), a similar ranking would be achieved.

Terrestrial gamma rays have been estimated to contribute about $30 \%$ of the total natural annual low-LET dose to bone marrow, most of the remainder being due to cosmic rays $(\sim 40 \%)$ and natural internal radio nuclides with the body $(\sim 30 \%)$ (Simmonds et al, 1995). If $20 \%$ of young persons' leukaemias are related to natural low-LET radiation, as has been suggested from standard radiological risk estimates for ages 0-24 (Simmonds et al, 1995; COMARE, 1996), then about $6 \%$ of these leukaemias may be attributable to terrestrial gamma rays. It is unlikely that a relative risk 
of this magnitude would be detectable in the present study after its statistical power, modest variations in dose rate and limitations of data collection are taken into account. Thus, the results of the study are reassuring, in that they do not indicate any measurable risk from natural gamma rays in the UK. Nevertheless, they do not contradict expectations of a small risk based on standard methods of risk assessment.

The results do not indicate either a positive or negative trend between gamma ray exposure and childhood cancer, the only exception being CNS tumours which show a weak (statistically not significant) positive trend. That one such trend should be observed when six groups are examined is hardly surprising. When the estimated mean cosmic ray dose rate is taken into account, the mean household terrestrial gamma-ray dose rate of $62.1 \mathrm{nGy} \mathrm{h}^{-1}$ is very similar to that found in the NRPB material (Wrixon et al, 1988) of $60.1 \mathrm{nGy} \mathrm{h}^{-1}$.

The increase in measured household exposure with increase in the deprivation index necessitated adjustment for socio-economic factors, but this makes no significant difference to the results. With the exception of the highest measured gamma-ray dose rate and radon concentration there was no evidence of any association between the gamma-ray and the results of the radon analysis. The number of households for which the highest levels of both were recorded (8) was, however, very small.

In conclusion, in line with standard risk estimates, the findings from this study are broadly reassuring.

\section{ACKNOWLEDGEMENTS}

The UKCCS was sponsored and administered by the United Kingdom Co-ordinating Committee on Cancer Research and was supported by the UK Children's Cancer Study Group (UKCCSG) of paediatric oncologists and by the National Radiological Protection Board. Financial support was provided by: Cancer Research UK, Leukaemia Research Fund, and Medical Research Council through grants to their units; Leukaemia Research Fund, Department of Health, member companies of Electricity Association, Irish Electricity Supply Board, National Grid Company plc, and Westlakes Research (Trading) Ltd for general expenses of the study; Kay Kendall Leukaemia Fund for associated laboratories studies; and Foundation of Children with Leukaemia for study of electrical fields. The investigation

\section{REFERENCES}

COMARE (1996) The incidence of cancer in young people in the vicinity of the Sellafield site, West Cumbria: Further studies and an update of the situation since the publication of the report of the Black Advisory Group in 1984. 4th Report, London: HMSO

Draper GJ, Vincent TJ, O’Connor GM, Stiller CA (1991) Socio-economic factors and variations in incidence rates between County Districts. In The geographical epidemiology of childhood leukaemia and non-Hodgkin's lymphomas in Great Britain, 1966-83. Draper G (ed) p 37

Muirhead CR, Butland BK, Green BMR, Draper GJ (1992) An analysis of childhood leukaemia and natural radiation in Britain. Radiation Protection Dosimetry 45: $657-660$

Richardson S, Montfort C, Green M, Draper G, Muirhead C (1995) Spatial variation of natural radiation and childhood leukaemia incidence in Great Britain. Stat Med 14: $2487-2501$

Stata Corporation (1998) Intercooled Stata 6.0 for Windows. Texas: Stata Corporation in Scotland is funded by The Scottish Office, Scottish Power plc, Scottish Hydro-Electric plc, and Scottish Nuclear Ltd. We thank the members of the UKCCSG for their support, the staff of the local hospitals, the family physicians and their practice staff, the staff technicians, and other staff, the members of the electricity industry in England, Wales, and Scotland and the school staff. We especially thank the families of the children included in the study.

\section{List of investigators}

Writing Committee: RA Cartwright, G Law, E Roman, E Gilman, OB Eden, M Mott , K Muir, D Goodhead, G Kendall.

Management Committee: KK Cheng, Central Region; N Day, East Anglia Region; RA Cartwright, A Craft, North East Region; JM Birch, OB Eden, North West Region; PA McKinney, Scotland; J Peto, South East Region; V Beral, E Roman, South Midlands Region; P Elwood, South Wales Region; FE Alexander, South West Region; CED Chilvers, Trent Region; R Doll, Epidemiological Studies Unit, University of Oxford; GM Taylor, Immunogenetics Laboratory, University of Manchester, Manchester; M Greaves, Leukaemia Research Fund Centre, Institute of Cancer Research; DT Goodhead, Medical Research Council, Radiation and Genome Stability Unit, Harwell; FA Fry, National Radiological Protection Board; G Adams, UK Co-ordinating Committee for Cancer Research.

Regional investigators: KK Cheng, E Gilman, Central Region; N Day, J Skinner, D Williams, East Anglia Region; RA Cartwright, A Craft, North East Region; JM Birch, OB Eden, North West Region; PA McKinney, Scotland; J Deacon, J Peto, South East Region; V Beral, E Roman, South Midlands Region; P Elwood, South Wales Region; FE Alexander, M Mott, South West Region; CED Chilvers, K Muir, Trent Region.

Leukaemia Research Fund Data Management Processing Group: RA Cartwright, G Law, J Simpson, E Roman.

A complete list of investigators is given in: The United Kingdom Childhood Cancer Study: objectives, materials, and methods. $\mathrm{Br} \mathrm{J}$ Cancer (2000) 82: 1073-1102
Simmonds J, Robinson C, Phipps A, Muirhead C, Fry F (1995) Risks of leukaemia and other cancers in Seascale from all sources of ionising radiation exposure. NRPB R276, Didcot, UK: HMSO

UNSCEAR (1993) Sources and effects of Ionising Radiation. New York: United Nations

UNSCEAR (2000) Sources and effects of Ionising Radiation. New York: United Nations

UK Childhood Cancer Study Investigators (2000) The United Kingdom Childhood Cancer Study: objectives, materials and methods. $\mathrm{Br}$ J Cancer 82: $1073-1102$

UK Childhood Cancer Study Investigators (2002) The United Kingdom Childhood Cancer Study of exposure to domestic sources of ionising radiation: 1: radon gas. $\mathrm{Br}$ J Cancer 86: $1721-1726$

Wrixon AD, Green B, Lomas $\mathrm{P}$ (1988) Natural radiation exposure in UK dwellings NRPB 190 Chilton: HMSO 